\title{
Serum uric acid level as a marker of cardiovascular disease in diabetic individuals
}

\author{
Sandhya Pillai Nair ${ }^{1}$, Sarthak Patel ${ }^{2}$ \\ ${ }^{1}$ Associate Professor, ${ }^{2}$ Tutor, Department of Biochemistry, Dr. M. K. Shah. Medical College and Research Centre, \\ Ahmedabad, Gujarat, India
}

Background: Serum Uric acid (SUA) had always been thought of as a metabolically inert end product of purine metabolism without physiological significance except gouty diathesis. However, it has been recently associated with insulin resistance and also considered as a risk marker for the development of diseases like diabetes, coronary heart disease. Aims and Objective: In this study we aim to determine the incidence of hyperuricemia in diabetic individuals and also study the relation of SUA with the other established risk factor of cardiovascular diseases, as it is one of the long term complications of Diabetes. Materials and Methods: The study enrolled 120 subjects. Group I (test group) comprised of 60 known cases of type II DM on oral anti-diabetic drugs. The control group comprised of 60 subjects who were non diabetic and not suffering from any major illness. The protocol of the study was approved by ethical committee of the institute. Total cholesterol, HDL, TG, glucose, SUA was estimated while parameters like LDL and VLDL were calculated. Results: A highly significant increased SUA, total cholesterol, HDL, TG, glucose, LDL and VLDL was seen in type II DM $(p<0.0001)$ when compared with control while a significant $(p<0.05)$ positive correlation was observed between SUA and total cholesterol and TG. In study group a negative correlation though not statistically significant was observed between SUA and fasting blood sugar level. Conclusion: SUA is definitely associated with development of complications of diabetes in the form of cardiovascular disease. This may be due to its influence on the deranged lipid metabolism and hyperglycemia.

Key words: Serum uric acid; Diabetes; Cardiovascular Disease; Lipid profile

\section{Access this article online}

Website:

http://nepjol.info/index.php/AJMS DOI: 10.3126/ajms.v12i1.31059

E-ISSN: 2091-0576

P-ISSN: 2467-9100

Copyright (c) 2021 Asian Journal of Medical Sciences

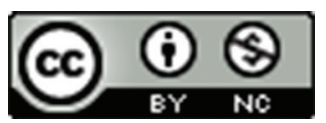

This work is licensed under a Creative Commons Attribution-NonCommercial 4.0 International License.

\section{INTRODUCTION}

Diabetes Mellitus was initially associated with hyperglycemia but subsequently linked as a great risk for all manifestation of atherosclerotic vascular disease, including stroke when compared with non diabetic subjects. ${ }^{1-3}$ This increased risk is only partly explained by the adverse effects of NIDDM on classic risk factors or risk factors clustering like hyperinsulinemia, elevated levels of total triglycerides, decreased HDL cholesterol, hypertension and glucose intolerance. ${ }^{4-6}$ There are more new risk markers which have been introduced like Serum uric acid (SUA).

Serum Uric acid or more correctly, its monoaninon uric acid at physiological $\mathrm{pH}$ values had always been thought of as a metabolically inert end product of purine metabolism without physiological significance except gouty diathesis. However, it has been recently associated with insulin resistance. ${ }^{7}$ It has been reported in some other research work that serum uric acid is also a novel risk factor for development of diabetes itself. ${ }^{8}$ Furthermore, in nondiabetic subjects an elevated level of uric acid has been shown to be an independent predictor of coronary heart disease and total mortality. ${ }^{9-11}$ At the same time studies done to determine the distribution of SUA in population of several countries have suggested that its levels are determined by both genetic and biological factors like gender, age and body mass. ${ }^{12-14}$

This means that SUA a risk factor (may be independent or dependent) of cardiovascular disease in diabetic individual is also genetically governed. So detection of this factor in 
Indian population and its relation with other risk factors becomes important. Since there is a higher incidence of diabetes and cardiovascular disease in Indian population which is thought to be genetically related and no significant study has been done in this direction to determine the level of uric acid in the Indian population and see how this risk factor is in turn related with the other risk factors.

Hence this study was planned out with a focus to determine if there was an incidence of hyperuricemia in Indian population and if yes, was there any correlation of it with other risk factors of cardiovascular disease among the diabetic Indian population.

\section{MATERIAL AND METHODS}

\section{a) Subject selection:}

The study enrolled 120 subjects admitted at Dhiraj Hospital, Piparia, Vadodara, Gujarat, India. The control group comprising of 60 subjects (non diabetic and not suffering from any major illness) who were sex and age matched and test group comprised of 60 subjects diagnosed as type II DM. They were known cases of diabetes and were treated only by oral anti-diabetic drugs (sulfonylurea and metformin). Patients with complications like history of stroke, myocardial infarction or any other cardiovascular disease were excluded. The known cases of hypertension were also excluded. The study protocol was approved by the Ethics Committee of the Institution. All ethical norms were followed during the entire course of the study.

\section{b) Collection of specimen:}

Venous blood sample was collected under aseptic conditions after 12 hrs of fast, in plain bulb for estimation of serum Uric acid, lipid profile while blood was collected in the fluoride bulb for blood sugar estimation both fasting and post prandial. The fasting blood sample was used for measurement of serum total cholesterol, HDL, TG, SUA while both fasting and post prandial sample was obtained to determine blood sugar level. These parameters were determined by using enzymatic reagent kits while parameters like LDL and VLDL was calculated using the formula (LDL = TC- $(\mathrm{HDL}+\mathrm{TG} / 5)$.Smoking, alcohol intake status were determined using standard questionnaires.

\section{Statistical analysis}

All results are expressed as mean \pm S.D. Students " $t$ " test was used to compare the continuous variables between groups. Pearson's correlation was employed to calculate the ' $r$ ' value. Statistical significance was defined as $\mathrm{p}<0.05$. The statistical analysis was done using SPSS version 14.0

\section{RESULTS}

The study group was divided into two - group I (diabetic individuals) while the group II (control). Table I summarizes the demographic data of participants in both the groups. There was no significant difference between the participants of both the groups with regards to age, sex, educational status, occupation, history of smoking and alcohol consumption.

All values are mean \pm SD. Total number of patients was 60 in each group. $\mathrm{p}<0.0001 *$ was considered to be highly significant.

The SUA levels observed in the test group could not be labeled as 'Hyperuricemic' but were definitely towards the higher side in the subjects than control group. The statistical analysis of the various parameters revealed that there existed a very highly significant correlation between the various parameters (BSL fasting, BSL post prandial, TC, TG, LDL, VLDL, UA) in test and control group (Table 2).

But when the correlation of serum uric acid with the other parameters was studied it was observed that a significant relation could not be established. Serum uric acid and fasting blood sugar showed a negative correlation. Two

\begin{tabular}{|c|c|c|}
\hline Parameter & DM (group I) & Healthy controls( group II) \\
\hline Age( years) & $55.7 \pm 9.7$ & $55.1 \pm 9$ \\
\hline Gender ( M:F) & $36: 24$ & $33: 27$ \\
\hline \multicolumn{3}{|l|}{ Smoking status } \\
\hline Never smoked & 33 & 21 \\
\hline Ex-smoker & 20 & 22 \\
\hline Current smoker & 7 & 17 \\
\hline \multicolumn{3}{|l|}{ Alcoholism } \\
\hline Never consumed & 30 & 28 \\
\hline Ex-consumer & 15 & 13 \\
\hline Currently alcoholic & 7 & 19 \\
\hline
\end{tabular}

\begin{tabular}{|c|c|c|c|c|}
\hline Sr. No. & Variables & Group I & Group II & $p$ value \\
\hline 1 & $\begin{array}{l}\text { Blood sugar (F) } \\
(\mathrm{mg} \%)\end{array}$ & $129 \pm 53.2$ & $78 \pm 12.6$ & $p<0.0001^{*}$ \\
\hline 2 & $\begin{array}{l}\text { Blood sugar (pp) } \\
(\mathrm{mg} \%)\end{array}$ & $210 \pm 76.5$ & $107 \pm 11.1$ & $p<0.0001^{*}$ \\
\hline 3 & Uric Acid (mg\%) & $6 \pm 1$ & $3 \pm 0.6$ & $p<0.0001^{*}$ \\
\hline 4 & $\begin{array}{l}\text { Total Cholesterol } \\
(\mathrm{mg} \%)\end{array}$ & $223 \pm 52.1$ & $165 \pm 27.4$ & $p<0.0001^{*}$ \\
\hline 5 & Triglycerides (mg\%) & $182 \pm 53.6$ & $114 \pm 32.5$ & $p<0.0001^{*}$ \\
\hline 6 & $\mathrm{HDL}(\mathrm{mg} \%)$ & $29 \pm 12.4$ & $44 \pm 12.9$ & $p<0.0001^{*}$ \\
\hline 7 & LDL (mg\%) & $158 \pm 51.6$ & $98 \pm 28.1$ & $p<0.0001^{*}$ \\
\hline 8 & VLDL (mg\%) & $36 \pm 10.8$ & $23 \pm 6.5$ & $p<0.0001^{*}$ \\
\hline
\end{tabular}


of the lipid profile parameters i.e total cholesterol and triglycerides showed a significant positive correlation in the test group (Table 3).

\section{DISCUSSION}

Diabetes is called a "Silent Killer" and with every new risk factor added, it becomes more difficult to understand the pathophysiology of this disease which seems to be so very interlinked with various other factors. The role of serum uric acid in development of cardiovascular disease in diabetic individuals is controversial. There are studies which have reported that serum uric acid is an independent risk factor for cardiovascular disease. ${ }^{15,16}$ While there are also some studies that found that it was not an independent risk factor but it acted so due to its association with other risk factors. ${ }^{17,18}$ It has been observed in these studies that this is because high body mass index (BMI), hypertension, lipid disorders (especially raised triglycerides level and low high density lipoprotein cholesterol HDL-C level), increased creatinine or insulin levels can lead to hyperuricemia.

In the present study also highly significant $(\mathrm{p}<0.0001)$ increase in the serum uric acid level was observed when compared with the control, which is very similar to the results of the other studies reported earlier. ${ }^{19-21}$ Hence we need to re think about Uric acid, as it no more looks to be a waste product but seems to have some more roles to play in the pathology of the disease. In fact the Finnish Diabetes Prevention Study states that serum uric acid level within the top tertile $(\geq 6.4 \mathrm{mg} / \mathrm{dl})$ is associated with a twofold increase in the risk compare to the lowest tertile $(<5.2 \mathrm{mg} / \mathrm{dl}) \cdot{ }^{21}$

Disturbed lipid metabolism another risk factor of CVD when studied revealed a highly significant positive $(p<0.0001)$ increase which was also indicated in another study. ${ }^{22}$ Uric acid was always considered to be an antioxidant with protective effect but with the recent clinical evidence suggesting that it also has toxic effects indicates that this paradox may be because of this compound becoming a

\begin{tabular}{|c|c|c|c|}
\hline \multirow[t]{2}{*}{ Sr. No. } & \multirow[t]{2}{*}{ Parameters } & \multicolumn{2}{|c|}{ Correlation coefficient(r) } \\
\hline & & Group I & Group II \\
\hline 1 & Blood sugar $(\mathrm{F})(\mathrm{mg} \%)$ & -0.045 & 0.096 \\
\hline 2 & Blood sugar (pp) (mg\%) & 0.082 & 0.14 \\
\hline 3 & Total Cholesterol (mg\%) & $0.44^{*}$ & 0.15 \\
\hline 4 & Triglycerides (mg\%) & $0.39^{*}$ & -0.081 \\
\hline 5 & $\mathrm{HDL}(\mathrm{mg} \%)$ & 0.06 & 0.1 \\
\hline 6 & LDL (mg\%) & 0.33 & 0.08 \\
\hline 7 & VLDL (mg\%) & 0.38 & -0.074 \\
\hline
\end{tabular}

pro- oxidant compound, particularly when it is present in blood at supranormal levels. The oxidative stress plays a significant role in the pathophysiology of the disease. ${ }^{23}$ The critical enzyme in the degradation to purine i.e Xanthine oxidase has been shown to be an important source of superoxide free radicals and its activity increases during ischemia. ${ }^{24,25}$ Hence an increased level of uric acid leads to endothelial dysfunction, oxidative metabolism, platelet adhesiveness, hemorrhage, aggregation and nitric oxide inhibition thus setting the ball rolling for episodes of cardiovascular disease. ${ }^{26}$

Serum uric acid and fasting blood sugar showed a negative correlation thus indicating that UA could be used as a potential biomarker to find the deterioration in glucose metabolism.

\section{CONCLUSION}

It can be concluded from this study that, though it cannot be stated that there exists incidence of hyperuricemia but definitely the values obtained of SUA are towards the higher side in the studied Indian population and it also correlation with some of the established risk factors of cardiovascular disease among the diabetic Indian population. The normal range has to be redefined in the Indian Population for serum Uric acid. Since, these findings provide prospective evidence that individual with though normal limits of serum uric acid have a risk to develop cardiovascular disease if the serum uric acid is towards the higher side of the normal range and hence it gets overlooked. It also seems that uric acid has an inextricably linkage with the dyslipidemia, deranged glucose metabolism thus contribute to the causal role in the pathogenesis of CVD. This study could be significant for the Indian population as they are at a higher risk of developing cardiovascular disease.

\section{REFERENCES}

1. Pyorala K, Laakso $\mathrm{M}$ and Uusitipa $\mathrm{M}$. Diabetes and Atherosclerosis: an epidemiologic view. Diabetes Metab Rev. 1987; 3:463-527. https://doi.org/10.1002/dmr.5610030206

2. Barrett Connor $\mathrm{E}$ and Khaw KT. Diabetes mellitus: an independent risk factor for stroke? Am J Epidemiol. 1988; 128: 116-123.

https://doi.org/10.1093/oxfordjournals.aje.a114934

3. Wolff PA, D Agostino RB, Belanger AJ and Kannel WB. Probability of stroke: a risk profile from Framingham Study. Stroke. 1991; 22:312-318.

https://doi.org/10.1161/01.STR.22.3.312

4. Lehto S, Ronnemaa T, Pyorala K and Laakso M. Predictors of stroke in middle aged patients with non insulin dependent diabetes. Stroke. 1996; 27:63-68.

https://doi.org/10.1161/01.STR.27.1.63 
5. Preis SR, Hwang SJ, Coady S, Pencina MJ, D'Agostino RB, $\mathrm{Sr}$, Savage PJ, et al. Trends in all-cause and cardiovascular disease mortality among women and men with and without diabetes mellitus in the Framingham Heart Study, 1950 to 2005. Circulation. 2009; 119: 1728- 1735.

https://doi.org/10.1161/CIRCULATIONAHA.108.829176

6. De Marco R, Locatelli F, Zoppini G, Verlato G, Bonora E and Muggeo M. Cause-specific mortality in type 2 diabetes. Diabetes Care. 1999; 22: 756- 76 .

https://doi.org/10.2337/diacare.22.5.756

7. Modan M, Halkin H, Karasik A and Lusky A. Elevated serum uric acid a facet of hyperinsulinemia. Diabetologia. 1987; 30:713-718. https://doi.org/10.1007/BF00296994

8. Dehghan $A$, van Hoek M, Sijbrands EJ, Hofman A and Witteman JC. High serum uric acid as a novel risk factor for type 2 diabetes. Diabetes Care. 2008; 31(2):361-362.

https://doi.org/10.2337/dc07-1276

9. Brand FN, Mc Gee DL, Kannel WB, Stroke J and Castelli WB. Hyperuricemia as a risk factor of coronay heart disease the Framingham study. Am J Epidemiol. 1985; 121:11-18. https://doi.org/10.1093/oxfordjournals.aje.a113972

10. Bengtsson C, Lapidus L, Stendahl C and Waldenstrom J. Hyperuricemia and risk of cardiovascular disease and overall death: A 12 year follow up of participants in the population study of women in Gothenburg, Swedan. Acta Med Scand. 1988; 224:549-555.

https://doi.org/10.1111/j.0954-6820.1988.tb19625.x

11. Levine W, Dyer AR, Shekelle RB, Schoenberger JA and Stamler J. Serum Uric acid and 11.5 year mortality of middle aged women: Finding of the Chicago Heart Association. Detection project in Industry. J Clin Epidemiol. 1989; 42; 257-267.

https://doi.org/10.1016/0895-4356(89)90061-9

12. Yanko K, Rhoads GG and Kagan A. Epidemiology of serum uric acid among 8000 Japanese American men in Hawaii. J Chron Dis. 1977; 30:171-184.

https://doi.org/10.1016/0021-9681(77)90083-2

13. Tumilehto J, Zimmer P, Wolf E, Taylor R, Ram P and King H. Plasma uric acid level and its association with diabetes mellitus and some biological parameters in a biracial population of Fiji. Am J Epidemiol. 1988:127; 321-336.

https://doi.org/10.1093/oxfordjournals.aje.a114807

14. Okada M, Takeshit M, Ueda K, Omae T and Hirota Y. Factors influencing the serum uric acid level. A study based on a population survey in Hisayama town. Kyushu, Japan. J Chron Dis.1980;33;607-12.

https://doi.org/10.1186/s12872-015-0116-z

15. Ito H, Abe M, Mifune M, Oshikiri K, Antoku S, Takeuchi Y, et al. Hyperuricemia is independently associated with coronary heart disease and renal dysfunction in patients with type 2 diabetes mellitus. PLos One. 2011; 6(11):e27817. https://doi.org/10.1371/journal.pone.0027817

16. Ioachimescu AG, Brennan DM, Hoar BM, Hazen SL and Hoogwerf BJ. Serum uric acid is an independent predictor of allcause mortality in patients at high risk of cardiovascular disease: a preventive cardiology information system (PreCIS) database cohort study. Arthritis Rheum. 2008; 58(2):623-630.

https://doi.org/10.1002/art.23121

17. Bruce F. Culleton, Martin G, Larson, William B. Kannel and Levy D. Serum Uric Acid and Risk for Cardiovascular Disease and Death: The Framingham Heart Study. Ann Intern Med.1999; 6(131):17-13.

https://doi.org/10.7326/0003-4819-131-1-199907060-00003

18. Chizynski $\mathrm{K}$ and Rozycka M. Is hyperuricemia a cardiovascular risk factor? Wiad Lek. 2006; 59(5-6):364-367.

19. Panero F, Gruden G, Perotto M, Fornengo P, Barutta F, Greco E, et al. Uric acid is not an independent predictor of cardiovascular mortality in type 2 diabetes: A population-based study. Athersclerosis. 2012; 221(1):183-188.

https://doi.org/10.1016/j.atherosclerosis.2011.11.042

20. Nan H, Pang Z, Wang S, Gao W, Zhang L, Ren J, et al. Serum uric acid, plasma glucose and diabetes.Diab Vasc Dis Res. 2010;7(1):40-46

https://doi.org/10.1177/1479164109347408

21. Niskanen L, Laaksonen DE, Lindstrom J, Eriksson JG, Keinänen-Kiukaanniemi K, llanne-Parikka $P$, et al. Serum uric acid as a harbinger of metabolic outcome in subjects with impaired glucose tolerance: the Finnish Diabetes Prevention Study. Diabetes Care. 2006; 29(3):709-711. https://doi.org/10.2337/diacare.29.03.06.dc05-1465

22. Rathmann W, Hauner H, Dannehl K and Gries FA. Association of elevated serum uric acid with coronary heart disease in diabetes mellitus. Diabete Metab. 1993;19(1 Pt 2):159-166.

23. Nair SP and Shah NC. Missing links between Central Obesity, Oxidative stress \& Glycemic levels in Diabetes. International Journal of Scientific Research. 2020;9(2):52-54. https://doi.org/10.36106/ijsr

24. Zweier JL, Kuppusamy P and Lutty GA. Measurement of endothelial cell free radical generation: evidence for a central mechanism of free radical injury in postischemic tissues. Proc Natl Acad Sci. U S A. 1988; 85:4046-4050. https://doi.org/10.1073/pnas.85.11.4046

25. Ashraf $M$ and Samra ZQ. Subcellular distribution of xanthine oxidase during cardiac ischemia and reperfusion: an immunocytochemical study. J Submicrosc Cytol Pathol. 1993; 25:193-201.

26. Nakagawa T, Tuttle KR, Short RA and Johnson RJ. Hypothesis: fructose-induced hyperuricemia as a causal mechanism for the epidemic of the metabolic syndrome. Nature Clinical Practice Nephrology. 2005;1(2) :80-86. https://doi.org/10.1038/ncpneph0019

\footnotetext{
Author's Contribution:

SPN - Concept design, Conducting test and analysis of results; SP - Manuscript preparation, critical revisions of the article. Both authors contributed to the intellectual development of this article.

Work attributed to:

Department of Biochemistry, Dr. M. K. Shah. Medical College and Research Centre, Ahmedabad, Gujarat, India.

Orcid ID:

Dr. Sandhya Pillai Nair - (10 https://orcid.org/0000-0002-6818-311X

Dr Sarthak Patel - (1) https://orcid.org/0000-0003-3144-6892

Source of funding: SBKSMI\&RC, Sumandeep Vidyapeeth, Vadodara, Gujarat, India, Conflict of Interest: None.
} 